\title{
The Strategy for the Development of Digital Education in Russia
}

\author{
E.B. Kolbachev ${ }^{1}$, A.A. Pakhomova ${ }^{1 *}$, T.I. Lomachenko ${ }^{2}$, and T.A. Kokodey ${ }^{3}$ \\ *Corresponding author: tivano@yandex.ru. \\ ${ }^{1}$ South-Russian State Polytechnic University (NPI), Russia \\ ${ }^{2}$ Sevastopol Branch of Plekhanov University of Economics, Russia \\ ${ }^{3}$ Sevastopol State University, Russia
}

\begin{abstract}
In a wide range of works of domestic and foreign scientists only some aspects of the digital economy are touched upon, which in the long run should develop into broader research. The authors' researches are aimed at forming a strategy for the development of digital education in Russia as the basis for implementing the national concept of "digital economy". To meet the requirements, the authors of the MBIC should pay more attention to the principles of management based on a cost approach, as well as to the interests of stakeholders in the planning and control of the achievement of goals. Stakeholders may be individuals, groups of individuals, institutions and organizations that influence the achievement of SSC goals and the implementation of their own goals, which in turn depend on the success of each SSCC author's activities.
\end{abstract}

Keywords: digitalization; education; strategy; strategy; network; national interest.

\section{Introduction}

At the present time, there is no common understanding of the concept of "digital economy" in scientific literature, so Doctor of Economics, corresponding member of the Russian Academy of Sciences Vladimir Ivanov suggests the widest definition of digital economy as a virtual environment that complements the existing reality [1]. R. Meshcheriakova, distinguishes between two approaches to the term "digital economy". The first approach is "classical": the digital economy is a digital economy and it is more appropriate to characterize only the field of electronic goods and services. The second approach is an extended one: "digital economy" is economic production using digital technologies [2]. The current work on the digital economy covers a wide variety of areas, such as the role of big data and application economics, standards for Smart Cities and the Internet of Things, vertical applications (e.g. workflow management and insurance telematics), and so forth.

\section{Problem Statement}

In addition, many domestic scientists, as well as foreign researchers consider cyberphysical systems as a key element of the digital economy.The essence of cyber-physical systems is that they link physical processes, such as manufacturing, with software and electronic systems. A.N. Raikov's contribution to the study of this issue is extremely great, and in his outstanding article [3] he pointed out the limitations of classical methods in solving the problem of education of schoolchildren and students, training of specialists of higher qualification taking into account the future needs of society (education for the future). This scientist proved that such a situation is connected with unreliable forecasting of needs, because the market can fluctuate in an unpredictable way. Specialist training, starting with kindergarten, is carried out in an environment of very high uncertainty. However, it is mainly based on retrospective knowledge and methods.

\section{Research Questions}

According to the study [4], the authors prove that the most stable and optimal structure of the education management system is a pyramidal three-level structure. At the same time, taking into account the development of the processes of horizontalization of relations between the subjects of the education system developing in the networked reflexive-active environment, it is possible to increase the levels of management. However, it is advisable to ensure proper control over the functioning of the system, monitoring and forecasting of market needs with appropriate modeling and theoretical justification.

If this study had not been carried out, it could have been argued that the existing works on digitalization of education cover only isolated aspects of individual areas of the digital economy and do not contain the development of comprehensive tools for effective management of the digital economy. However, the above work [4] considers ways and directions of further development of the system of strategic management of digital education development in the Russian Federation (SSMDEDIRF). 


\section{Purpose of the Study}

The aim of the study is to develop the strategy of digital education of the Russian Federation as the basis for the implementation of the concept of "Digital economy". The authors of the article in their work explore the risks and threats facing the education system. They consider it necessary to increase the competitiveness of the country's economy through the tools of the educational system.

\section{Research Methods}

In order to create a conceptual model and management mechanism for the formation and operation of the system of strategic management of digital education development in the Russian Federation, it is necessary to clearly define the goals of digitalization in Russia in general and the digitalization of education, in particular, the formation of development trajectories leading to the achievement of such goals. These trajectories are formed by selecting a set of expedient management decisions of organizational, technical and other nature, ensuring a synergetic effect in the practical implementation of the decisions made.

Many possible solutions (initially of a chaotic nature) serve as an information base for the formation of alternative options for the trajectories of innovative development of SSMDEDIRF. One (or several) of these alternative trajectories in the process of competitive (quasi-competitive) procedures becomes/become dominating/dominant. This is a concrete embodiment of the rational choice of authors, carried out in specific conditions and under certain preferences.

In the context of our study, the issue of the goals of digitalization in general and innovation related to digitalization (including the digitalization of education) is important. This issue can be solved by considering the axiological aspects of digitalization - aspects related to the nature of the values of education and innovation, the interaction of different values among themselves.

Taking into account these values $[5,14,15]$, it can be argued that the formation of a strategic management system for the development of digital education (SMSDDE) at the national level should solve the following problems: the formation of the conceptual provisions of the SSD; the formation of the composition of subjects of the digital education system; the formation of a system of interaction between the subjects of the digital education system; the formation of a system of resource support of SSD activities :in this case, the subjects of the digital education system include: public educational institutions of general secondary education; public educational institutions of secondary professional education; public educational institutions of higher education; individuals - developers and rightholders; state educational authorities of different levels; elements of the digital education system infrastructure; Federal Analytical and Project Center for Digital Education (SSC); Distributed Regional Situation Centers for Digitalization of Education (RSCFDE); Smart-Centers of educational organizations;

The nature of interaction between subjects of the digital education system is determined by the following features: a) organizational (including legal) independence of subjects; b) competitive nature of relations between developers and other subjects of SSC; c) the presence of common goals and objectives of activity determined by the interests of the Russian state and society as a whole. In this case, point "c" seems to be extremely significant, as it is directly related to the above axiological aspects of the digitalization of education.

On the basis of the above, it can also be stated that the quantitative assessment of the development of the socioeconomic system (SES), for the sake of which digital education is created, can be made on the basis of determining the volume of information contained in it, and the entropy of SES. With regard to socio-economic systems as a whole, a similar conclusion was made by V. Maevsky in his famous work [6]. In particular, he found that economic evolution can be presented as a process of increasing negative entropy of the economic system. At the same time there are processes of complication of economic relations and ordering of the internal structure of the system.

\section{Findings}

The above described nature of interaction between the subjects of SSC allows to assert that the set of subjects of the digital education system forms a business network $(\mathrm{BN})$, the specifics of which should be taken into account in the formation of SSCS. The information stage of economic and social development was marked, among other things, by the strengthening of the authors' integration, which made it possible to speak about the formation by the end of the nineties of a new economic reality - the global SES, which, in turn, consists of numerous networks based on new methods of integration in the implementation of joint projects related, in particular, to the introduction of computer (digital - in modern terminology) technologies $[6,7,8]$.

Such BN factors as risk sharing and optimization of information management are very important for understanding possible goals and objectives of domestic SSC. In fact, participation in the business network may become the most important way for the Russian subject of SSC to increase the stability of functioning, especially in the conditions of modernization of educational processes (part of the risks is removed and functioning conditions are stabilized).

Conventionally, the situation in the network organization can be represented in the form of "abstract of the socioeconomic world", which received further development in works by Y. V. Shishkov, M. Shpagina. [9,10]. The main feature of this model is the hypothesis that there are differences in the parameters of information exchange between 
participants of joint activity. According to this model, the social space in which the participants of the joint activity are distributed has a non-zero information permeability. The specific values of information permeability are determined by the level of development of information and communication technologies and mean that information from point $\mathrm{A}$ to point $\mathrm{B}$ of the space reaches a certain time, which is the greater the "distance" between these points in accordance with the topology of information dissemination in it. Accordingly, the longer the time that information is disseminated, the more likely it is to become outdated due to constant changes in the state of the economic space at each point. The first group is located within a radius of RO equal to the maximum distance from point $\mathrm{A}$, at which it is still possible to exchange information intensively enough to use the community form of management. The second group is outside the radius of the RO, but inside the border with a large radius of RE. The RE distance is the maximum, at which the information exchange, sufficient for the functioning of the hierarchical form of control, is possible. All participants of the second group can potentially establish hierarchical relations with the "observer", but they can no longer establish communitarian relations. The third group is beyond the RE radius, and therefore the "observer" can interact with them on the basis of an even less information-intensive form of control.

With the development of digitalization, there is an increase in the speed of information dissemination, which leads to an increase in the length of the RO and RE radii and, consequently, the boundaries of the zone where community-based and/or hierarchical forms of control can be applied are extended. Theoretically, the network structure has no clear boundaries. In the literature [11] only the main subsystems forming the network organization are singled out: the corporate center; the subsystem of service organizations; members of the network. In the context of SSC, their roles are performed by the entities that support the activity of SSC (Federal Analytical and Project Center of SSC (FAPCSSC); distributed regional situational centers of digitalization of education (DRSCDE); Smart-Centers of educational organizations), as the infrastructure of SSC (ISSC).

It is advisable to entrust the Corporate Center (FAPCSSC) with the functions of coordinating the interests of all network members, representing them in relations with third parties, coordinating and supporting the corporate image of the network. In addition, the Corporate Centre FAPCSSC ensures interaction between the members of the network (it is an information and communication center).

In our opinion, such an approach can be adopted as a basis with the reservation that the allocation of FAPCSSC plays a functional rather than a structural role: the same organizations can be members of the network and at the same time perform infrastructural service functions for the whole $\mathrm{BN}$.

Members of the network in terms of access and participation in the work of the network can be subdivided into: valid, i.e. having access to all functionalities of the network and participating in the work of the network directly; associated, i.e. having access not to all functionalities of the network (access to the network can be organized through one of the full members).

The place and nature of the links vary: members of the first level network who are in constant interaction with other members of the network as well as with FAPCSSC; members of the second and subsequent levels who interact with the group of members of the network and have almost no interaction with FAPCSSC.

The degree of interaction in the network organization can be characterized by the density of interaction, defined as the ratio of the number of real interactions between members of the network to their theoretically possible number:

$$
P(t)=\operatorname{Ir}(t) / \operatorname{Im}(t) * 100
$$

where $\mathrm{P}(\mathrm{t})$ is the network density at time $\mathrm{t}$;

$\operatorname{Ir}(\mathrm{t})$ - number of real interactions at the moment $\mathrm{t}$;

$\operatorname{Im}(\mathrm{t})$ - number of mathematically possible interactions at the moment [12].

The study of L. Hirschhorn describes the advantages of a network organization as follows: «Network organizations are characterized by the creation of better communications than the market can do, network forms of organization provide better coordination in the face of changes, the significance of which cannot be fully conveyed or understood through price signals. The last seems to be the most important in the context of our research. As has been shown above, commercial criteria for the efficiency of modernization projects are not objective enough. This is one of the examples of inefficiency of "price signals" discussed in the above paper» [12, p.56].

By their very nature, classic networks are close to coalitions - voluntary associations formed to achieve common goals and objectives. Such a view of networks as polycentric informalized structures is characteristic of the European research tradition. The American authors, on the contrary, tend to interpret networks in a more formal way, emphasizing the moment of deep interdependence of participants and noting the possibility of the presence in the networks of a single control center in the person of the company - network integrator. In general, the scientific literature presents a wide range of definitions of networks in the absence of a common interpretation.

There is an opinion that the closest to the practical understanding of networks is the definition of F. Kotler and R.S. Achrol, as it indicates the lack of hierarchical control in the network organizations, but at the same time it notes the presence of common goals among the participants. Involvement, the authors summed up, «is the main difference between the network concept and the traditional theory of organization» [13, p.10].

The natural interest to the network form of SSC is connected with revealing of the mechanism coordinating network interactions as, without assuming the presence of administrative apparatus of compulsion, simultaneously provides joint work of subjects. Unlike hierarchies based on internalization (assignment) as a way to ensure integration processes, the network is an organizational and management form based on externalization (alienation). 


\section{Conclusion}

Strategic organizational challenges related to the competitive nature of the relationship between developers and other SSC entities appear to be quite complex and important, given that competitiveness (CS) is a complex, multi-level concept whose analysis and evaluation should be linked to the type and geographical scope of the competitive field. Therefore, the formation and analysis of the system of factors and indicators characterizing SSC in the market of educational services, it is advisable to consider in the context of competitive processes at the macro and meso-levels.

It is obvious that the factors determining the CS of the SSC authors at macro- and meso-levels are external to them. It should be noted that the existing interrelation between the factors is bilateral in nature. On the one hand, a favorable socio-economic and political climate, formed at the macro level, is extremely important for the CS of SSC authors. On the other hand, the CS of education in the country depends on the ability of all subjects to build effective chains of intellectual products, their ability to create and develop competitive advantages and influence the formation of socio-economic policy of the state.

\section{Acknowledgments}

The work is executed at financial support of Russian Foundation for basic research under research project 19-01000377 "Designing the strategic management system development digital education of the Russian Federation".

\section{References}

1. The World Bank, Development of the digital economy in Russia. World Report 20 December 2016 (2016). URL: https://www.vsemirnyjbank.org/ru/events/2016/12/20/developing-the-digital-economy-in-russia-internationalseminar-1. Accessed: 13.10.2019. [in Rus.].

2. RIA NOVOSTI, Digital economy: How experts understand this term (2017). URL: https://ria.ru/20170616/1496663946.html. Accessed: 02.09.2019. [in Rus.].

3. A. Raikov, Accelerating technology for self-organising networked democracy. Futures, 103, 17-26 (2018). DOI: 10.1016/j.futures.2018.03.015. [in Rus.].

4. T.I. Lomachenko, T.A. Kokodey, E.B. Kolbachev, A.A. Pakhomova, Development of the pyramidal conception of the Russian Federation digital education development strategy formation. Druckerovsky Vesnik, 3, 134-141 (2019). DOI: 10.17213/2312-6469-2019-3-134-141. [in Rus.].

5. E.B. Kolbachev, Social effectiveness of organizational and economic decisions affecting the development of higher education in the regions of Russia. Bulletin of the South Russian State Technical University (NPI). Series: SocioEconomic Sciences, 1, 118-124 (2012). [in Rus.].

6. V. Maevsky, Economic evolution and economic genetics. Economics, 5, 4-21 (1994). [in Rus.].

7. L.A. Volovik, Fundamentals of foreign economic activity (KSU, Kaliningrad, 1998). [in Rus.].

8. N.V. Khmel'kova, Network management in marketing. Practice of domestic metallurgical companies. In S.S. Chernova (Ed.), Problems of Economics and Management of Enterprises, Industries, Complexes (pp. 198-207). Novosibirsk: ZRNS (2009). [in Rus.].

9. Yu.V. Shishkov, Globalization of economy - A natural product of industrialization and informatization of society (IMEMO RAN, Mocsow, 2016). [in Rus.].

10. M. Shpagina, Revision. Should we reject the values of the new economy. Expert, 10.09.2001 (2001). [in Rus.].

11. B.L. Kuznetsov, A.A.Galiakberova, Synergetic effect of the technopolis development of the region. Economic Synergetics and Innovation Process (abstracts of Interuniversity scientific and practical conference) (pp. 42-43). Nabereznye Chelny: Kampi publishing house (1998). [in Rus.].

12. L. Hirschhorn, Beyond mechanization: Work and technology in a postindustrial age (MIT Press, Cambridge, MA, 1986).

13. F. Kotler, R.S. Achrol, Marketing in the network economy. Journal of Marketing, 63, 146-163 (1999). DOI: 10.2307/1252108. [in Rus.].

14. E.B. Kolbachev, A.A. Pakhomova, Designing the system of strategic management of digital education development in the Russian Federation: Some methodological features. In T.I. Lomachenko (Ed.), Proceedings of the III Interdisciplinary All-Russian Scientific Conference: Development of methodology of modern economic science, management and education in the conditions of information-digital trends (pp. 136-145). Sevastopol: Sevastopol branch of the "Russian Economic University named after G.V. Plekhanov" (2019). [in Rus.].

15. E.B. Kolbachev, A.A. Pakhomova, Development of digital education in Russia: Some strategy issues. Druckerovsky Vestnik, 4, 162-172 (2019). DOI: 10.17213/2312-6469-2019-4-162-171. [in Rus.]. 